\title{
A AMBIGUIDADE PRESENTE NA RELAÇÃO DE NIETZSCHE COM O CETICISMO
}

\author{
THE AMBIGUITY PRESENT IN NIETZSCHE'S RELATIONSHIP WITH SKEPTICISM
}

Francisco Alvarenga Junnior Neto*

\begin{abstract}
RESUMO
Este artigo se pretende a uma discussão acerca da relação entre Nietzsche e o ceticismo. Em algumas passagens o filósofo realiza elogios aos céticos, porém, em outras, ele passa a referirse a eles como decadentes. Ainda, em determinados momentos de seu texto, Nietzsche reclama para si outro tipo de ceticismo: experimental e criador que, visto mais de perto, não se identifica com as versões do ceticismo afirmadas durante a história da Filosofia. Dessa maneira, a fim de compreendermos a ambiguidade presente na relação de Nietzsche com o ceticismo, dividimos nosso trabalho em três seções. Na primeira, buscar-se-á explicitar a compreensão que o filósofo possui sobre a questão da verdade, em contrapartida ao entendimento dogmático. Na segunda seção o objetivo será discutir as formas como o ceticismo aparece no texto nietzschiano, com o intuito de clarificar a visão do filósofo sobre esta tradição. Por fim, na terceira seção, o texto se desenvolverá apresentando a voz cética de Nietzsche. Esta sua voz não se identifica com as vozes céticas de outrora. O ceticismo nietzschiano - criador - não aceita a paralisação da vontade, pelo contrário, ganha vida em prol da criação de possibilidades novas e engrandecedoras de si.
\end{abstract}

PALAVRAS-CHAVE: Ceticismo. Criação. Filosofia do futuro. Nietzsche. Verdade.

\section{ABSTRACT}

This article is intended to discuss the relationship between Nietzsche and skepticism. In some passages the philosopher praises the skeptics, but in others, he comes to refer to them as decadents. Still, at certain moments of his text, Nietzsche claims to himself another type of skepticism: experimental and creator which, seen more closely, does not identify with the versions of skepticism affirmed during the history of Philosophy. Thus, in order to understand the ambiguity present in Nietzsche's relationship with skepticism, we divided our work into three sections. In the first, it will be sought to explain the understanding that the philosopher has about the question of truth, in contrast to dogmatic understanding. In the second section the objective will be to discuss the ways in which skepticism appears in the nietzschian text, in order to clarify the philosopher's view of this tradition. Finally, in the third section, the text will develop with Nietzsche's skeptical voice. This voice of his does not identify with the skeptical voices of yored. The nietzschian skepticism - creator - does not accept the paralyzing of the will, on the contrary, comes to life for the creation of new and aggrandizing possibilities of oneself.

KEYWORDS: Skepticism. Creation. Philosophy of the future. Nietzsche. Truth.

\footnotetext{
${ }^{*}$ Mestre em Filosofia pela Faculdade Jesuíta de Filosofia e Teologia (FAJE). Graduado em filosofia pelo Instituto Santo Tomás de Aquino (ISTA). E-mail: franciscocmf@gmail.com.
}

Sapere aude - Belo Horizonte, v. 11 - n. 21, p. 259-275, Jan./Jun. 2020 - ISSN: 2177-6342 


\section{INTRODUÇÃO}

Embora não haja dúvidas quanto à importância de alguns temas para os estudiosos da filosofia de Friedrich Nietzsche, não há um consenso quanto à importância do ceticismo. Falar sobre qualquer assunto que envolva Nietzsche já se mostra uma tarefa extremamente ousada, dado o excesso de textos, estudos, teses e dissertações que se produziram sobre o importantíssimo filósofo alemão. No entanto, como qualquer clássico, os assuntos sempre podem ser revisitados e reinterpretados à luz de novas teorias e formulações, e é este um dos motivos pelos quais este texto ganha vida.

Nossa intenção aqui é evidenciar a relação existente entre Nietzsche e o ceticismo - que não é algo nada simples de se realizar, dada sua complexidade e ambiguidade -. Até então, o interesse de Nietzsche pelo ceticismo ganhou atenção em textos como Nietzsche on the Skeptics and Nietzsche as Skeptic (2000), de Richard Bett (2000), Friedrich Nietzsches "Der Antichrist". Ein philosophischhistorischer Kommentar (2000) e Nihilism and Skepticism in Nietzsche (2006), de Andreas Urs Sommer, e Ceticismo e vida contemplativa em Nietzsche (2008), de Rogério Lopes, nos quais os autores demonstram a importância do ceticismo não apenas como uma tradição com a qual Nietzsche realiza interlocuções, mas também como uma influência importantíssima para o desenvolvimento de sua visão filosófica acerca da vida.

Em Nietzsche, o ceticismo comparece atuando em duas frentes: sobre o filósofo e através do filósofo. Primeiro, sobre o filósofo, porque o contato com as teses céticas é fundamental para a sua mudança de perspectiva, tornando-lhe quase indiferente ao conteúdo dos argumentos dogmáticos, e possibilitando a ele um olhar crítico sobre eles e sobre seus efeitos no desenvolvimento da cultura ocidental; e segundo, através do filósofo, visto que por ele o ceticismo é reinventado e toma tons de suas próprias preocupações e discussões.

O que se segue não é uma tentativa de sistematizar as abordagens de Nietzsche sobre o ceticismo, mas discutir como o ceticismo colabora para o desenvolvimento de sua tarefa filosófica de criação e experimentação, presente fortemente no período tardio de sua obra ${ }^{1}$. Neste contexto, será útil, primeiramente, analisarmos como se desenvolve no pensamento nietzschiano o tema da verdade; ou seja, qual é o trato que o filósofo alemão dá a este tema. Güntel Abel, chama-nos a atenção para o fato de a palavra "Verdade" ser a palavra chave da

\footnotetext{
1 "Obra tardia" é uma das maneiras de se referir ao período de 1882 a 1888, marcado pelas publicações de Assim falou Zaratustra, Além de bem e mal, Genealogia da moral, O Crepúsculo dos ídolos, O anticristo, Ecce homo, por exemplo.
}

Sapere aude - Belo Horizonte, v. 11 - n. 21, p. 259-275, Jan./Jun. 2020 - ISSN: 2177-6342 
filosofia ocidental (ABEL, 2005, p. 179), que em Nietzsche ganha uma discussão de várias faces, as quais buscaremos salientar.

Na sequência, nossa intenção será apresentar como a presença do ceticismo nas obras de Nietzsche é ambígua, visto que não são poucas as vezes que o filósofo realiza críticas a esta tradição, da mesma forma que não são poucas as vezes que ele realiza elogios a ela. Uma das motivações para a ambiguidade encontrada nesta relação se deve ao fato de que o corpus de Nietzsche dedicado ao ceticismo não é tão extenso ou proeminente como aquele dedicado a Sócrates e Platão, por exemplo. Outra motivação para isto é o fato de que, apesar de encontrarmos várias passagens em que Nietzsche utiliza os termos "cético" e "ceticismo", não é claro que ele esteja se referindo ao ceticismo filosófico (BETT, 2000, p. 67).

Por fim, após apresentarmos a ambiguidade constante na relação do filósofo alemão com o ceticismo, a proposta será, partindo de textos da obra tardia de Nietzsche, como Além de bem e mal e $O$ anticristo, reivindicarmos uma certa conciliação do filósofo para com esta tradição. Como veremos, nas obras deste período, o filósofo reclama para si um ceticismo "viril" e "experimental" (BM, §209-211), o que contraria o temperamento do cético grego que, segundo ele, é marcado por uma paralização da vontade de vida (KSA XIII, 15 [58]).

Por fim, ao propormos este itinerário, esperamos que, de alguma maneira, fique claro que a importância de se pensar a relação entre Nietzsche e o ceticismo não é de maneira alguma lateral, mas extremamente importante para compreendermos sua filosofia, suas interações e discussões com a tradição, bem como os desdobramentos que daí se seguem.

\section{A QUESTÃO DA VERDADE}

Já chamaram meus livros de uma escola da suspeita, mais ainda do desprezo, felizmente também da coragem, até mesmo da temeridade. De fato, eu mesmo não acredito que alguém, alguma vez, tenta olhado para o mundo com mais profunda suspeita (HH, Prefácio $\S 1)$.

Quando tratamos do desenvolvimento da filosofia no Ocidente, constatamos que ela foi edificada sobre uma perspectiva de leitura da realidade. Tal perspectiva, analisada em seu âmago, apresenta que a crença na verdade foi o grande alicerce fundante do pensamento ocidental. Desde discussões acerca da moral e da ética até discussões que tocam à validade do conhecimento científico, todas elas estão relacionadas, em alguma medida, ao problema da verdade. Desta maneira, não faltam filósofos e perspectivas que têm como objetivo definir, 
afinal, o que é a verdade ${ }^{2}$. Entre eles, porém, com uma posição que destoa da grande maioria, encontra-se Nietzsche, para quem a verdade não é um objeto simples de se definir.

Desde já, devemos partir do princípio de que para Nietzsche é clara a sua tarefa - que se relaciona com todo o seu construto filosófico - de colocar em questão, experimentalmente, o valor da verdade, como ele nos apresenta na Genealogia da moral (GM III, §24) ${ }^{3}$. Retornando a um ponto posto anteriormente, falar da verdade em Nietzsche não é algo simples, dada a quantidade de significados que esta palavra ganha em suas elucubrações. Dentre as formas de Nietzsche tratar o tema da verdade, nesta seção, buscaremos salientar uma: a verdade não como um valor lógico, mas como um valor moral.

Quando Nietzsche, na Genealogia da moral, afirma que se deve colocar em questão o valor da verdade, isto não significa que se deva considerar válida ou não uma concepção acerca daquilo que é tomado como verdade; não se trata de realizar uma substituição de uma compreensão por outra. Muito pelo contrário, conforme aponta Güntel Abel, "é a arquitetura do questionamento mesma do sentido da verdade, que é reinterpretada" (ABEL, 2005, p. 180). Com isto, ao pensar a questão da verdade em Nietzsche, temos de perceber que o filósofo ultrapassa aquela configuração antinômica existente entre os conceitos - fruto da idiossincrasia filosófica (bem e mal, bom e ruim, verdadeiro e falso) - e apresenta a verdade (a afirmação acerca da verdade) não como um ato que diz respeito a uma manifestação pelo uso da razão, tampouco como desvelamento de uma realidade metafísica - uma interpretação -, mas como um processo (KSA VII, 2 [151]). E já aqui, temos exposta a intenção nietzschiana de efetuar uma crítica radical à metafísica. "O ato de verdade" passa a ser compreendido como um acontecimento (STEGMAIER, 2013, p. 49); em outras palavras, aquilo que é definido como verdade perde sua estabilidade fixa, tendo em vista que "não há nenhuma verdade" (KGW VIII, 2 [108]. Tradução nossa).

Verdade não é, por conseguinte, algo que existiria aí e poderia ser encontrado ou descoberto, mas sim algo a ser criado e que dá nome a um processo, mais ainda, a

\footnotetext{
${ }^{2}$ A palavra verdade pode ser compreendida na filosofia, geralmente, de três maneiras: como concordância, como auto justificação e como resultado de uma determinada atividade filosófica. Independente da forma como se prefira compreendê-la, o pressuposto que se tem é de que não existem muitas verdades, mas apenas uma, para a qual se voltam todos os esforços argumentativos afim de alcançá-la.

${ }^{3}$ Adotamos a convenção proposta pelos Cadernos Nietzsche de citação das obras de Nietzsche utilizadas. Desta maneira, as abreviações utilizadas neste trabalho são as seguintes: KSA = Sämtliche Werke. Kritische Studienausgabe $; \mathbf{K G W}=$ Sämtliche Werke. Kritische Gesamtausgabe $; \mathbf{B V N}=$ Cartas de Nietzsche $($ conforme a eKGWB); AC = O anticristo; $\mathbf{G M}=$ Genealogia da moral $; \mathbf{H H}=$ Humano, demasiado humano $; \mathbf{G C}=A$ Gaia Ciência $; \mathbf{B M}=$ Além do bem e do mal; $\mathbf{E C}=$ Ecce homo; VM = Sobre verdade e mentira. Outra abreviação utilizada é $\mathbf{H P}=$ Hipotiposes pirrônicas, de Sexto Empírico.
} 
uma vontade de subjugar que, em si, não tem fim: insinuar a verdade como um processos in infinitum, um determinar ativo, não um tomar-consciência de algo <que $>$ seria 'em si' fixo e determinado. Eis um lema (Wort) para a "vontade de poder" (KGW VIII, 9 [91]. Tradução nossa).

Como compreende Nietzsche o que é a verdade neste fragmento, ela é uma representação de uma vontade: vontade de verdade. Adi Parush, partindo desta interpretação, propõe que a vontade de verdade não designa um fenômeno epistemológico, como a busca de uma verdade pragmática, mas como busca de uma determinada forma de vida (PARUSH, 1976, p. 529). Assim, temos de compreender que esta vontade de verdade se encontra relacionada negativamente com a vontade de poder, pois enquanto Nietzsche desenvolve a doutrina da vontade de poder como uma alternativa à metafísica (KGW VIII, 14 [81]), a vontade de verdade tem como princípio preservar uma realidade por meio da imposição de significados (KAIN, 1983, p. 369-370). Logo, ao tomar a vontade de verdade como um ponto a ser discutido, temse de ter claro que o que ela designa não é outra coisa senão uma vida que toma como princípio a crença de que não há nada mais importante do que o verdadeiro. Roberto Machado compreende que uma vida que tem como pressuposto a vontade de verdade é aquela em que o verdadeiro é tomado como superior ao falso, em que a verdade é um valor superior. Em suma, que a vontade de verdade é a expressão de uma vontade negativa de potência (MACHADO, 2017, p. 15).

Se a reconstrução feita aqui estiver correta, e a vontade de verdade designar uma vontade de uma determinada maneira de existência, quando nos deparamos com a defesa de uma verdade ou de um caminho a se chegar a ela, o que devemos investigar é qual tipo de vida que se está buscando. Outrossim, a vontade de verdade pode ser compreendida como um dos fenômenos pelos quais vem a público uma necessidade, em virtude da conservação de um determinado tipo de vida. Para o filósofo alemão, todo conhecimento, e com ele a vontade de verdade, envolve uma projeção de uma perspectiva (KAIN, 1983, p. 367) ou, em outras palavras, todas as regras que delimitam o complexo da verdade passam a ser vistas como convenções, estruturas, que buscam impor disciplina através do intelecto ${ }^{4}$.

Enquanto o indivíduo, num estado natural das coisas, quer preservar-se contra outros indivíduos, ele geralmente se vale do intelecto apenas para a dissimulação: mas,

\footnotetext{
${ }^{4}$ Rogério Lopes, sobre este aspecto, defende que Nietzsche explora a hipótese contratualista. "Num hipotético estado de natureza haveria uma espécie de uso privado do intelecto, como uma faculdade de representações para fins de sobrevivência do indivíduo. [...] o contrato equivale ao estabelecimento de um mundo comum, sancionado por regras que garantem a uniformidade das representações por meio de uma homogeneidade nas designações" (LOPES, 2006, p. 72).
} 
porque o homem quer, ao mesmo tempo, existir socialmente e em rebanho, por necessidade e tédio, ele necessita de um acordo de paz e empenha-se então para que a mais cruel bellum omnium contra omnes ao menos desapareça de seu mundo. Esse acordo de paz traz consigo, porém, algo que parece ser o primeiro passo rumo à obtenção daquele misterioso impulso à verdade (VM, p. 29).

Nietzsche vai além de qualquer lógica binária em se tratando de qualquer assunto que envolva a verdade. Nietzsche admite que a verdade é um valor e, em certa medida, a filosofia nietzschiana tem como o centro de suas discussões o tema do valor (MACHADO, 2017, p. 16). Com isso, quando dizemos de uma verdade, dizemos, também, de um valor engendrado sob uma determinada perspectiva - determinada avaliação - que, em suma, carrega uma vontade. Assim, expressa o filósofo alemão que se a verdade é definida por perspectivas, o mundo que nomeamos como realidade, nada mais é que aparência.

A fundo, quando tomamos esta concepção como ponto de partida, outra questão que nos acomete é: o que há por de trás da ânsia pelo conhecimento? Nietzsche vê nessa vontade um tipo de homem que busca a tranquilidade, haja vista que "[c]onhecer também é ter o controle sobre o que se conhece, o que transmite a sensação de paz e uma postura de se poder ditar a verdade" (SOUSA, 2011, p. 32). No âmago de nossa consciência da realidade - ou pelo menos daquilo que acreditamos ser consciência da realidade ou de qualquer outra coisa -, estamos envoltos por um dogmatismo inconsciente (GIACOIA JÚNIOR, 1997, p. 128). Em Além de bem e mal, em seu prefácio, Nietzsche chega a afirmar que a história da Filosofia é a história da vontade de verdade (BM, § 1).

Não obstante, contrário ao que parece, Nietzsche não é um falabilista empírico, para quem nenhuma declaração é possível (PARUSH, 1976, p. 526). O filósofo, apesar de rechaçar a crença na existência de uma verdade universal, não nega a possibilidade de verdades possíveis, a depender da perspectiva em que se está afirmando-as (MAGNUS, 1980, p. 265). Nietzsche não defende que não exista uma verdade; para ele "há uma verdade, não absoluta, mas criada" (BELLORO, 2015, p. 67. Tradução nossa).

Destarte, isso nos impossibilita alinhar Nietzsche aos filósofos dogmáticos - ao menos aos dogmáticos "positivos". Com isto, na próxima seção buscaremos discutir a presença e a relação de Nietzsche com o ceticismo. Aí, o pano de fundo de nossa discussão será a compreensão nietzschiana acerca da verdade, exposta nesta seção, bem como a sua compreensão acerca do tipo cético (principalmente antigo). 


\section{A AMBIGUIDADE DO CETICISMO EM NIETZSCHE}

O novo em nossa posição atual perante a filosofia é uma convicção que nenhuma época jamais teve: a de que nós não temos a verdade. Todos os homens do passado "tinham a verdade": até mesmo os céticos (KGW V, 3 [19]. Tradução nossa).

Por meio de trabalhos como o realizado por Rogério Lopes em sua tese doutoral, intitulada Ceticismo e vida contemplativa em Nietzsche (2008), a questão sobre se Nietzsche sofreu influências do ceticismo pode ser considerada como respondida positivamente. Estudos acerca da influência do ceticismo sobre ele demonstram seu crescente interesse pelo ceticismo a partir do ano de $1866^{5}$. Apesar de esta constatação positiva, a relação de Nietzsche com o ceticismo não é nada simples. Qualquer pessoa que tenha um certo contato com a obra nietzschiana e com ceticismo pode encontrar similitudes entre suas filosofias, bem como diversas referências a eles. Estas referências, apesar de demonstrarem o seu conhecimento sobre o ceticismo, trazem um problema ao leitor por serem ambíguas. De qualquer maneira, seja nas afirmações explicitas seja nas implícitas de Nietzsche sobre o ceticismo, encontramos a sua influência sobre ele. Neste sentido, sobre a questão se Nietzsche é um cético? A resposta é sim e não (CLARK, 1990, p. 60); e é isto que buscaremos evidenciar nesta seção ${ }^{6}$.

Preliminarmente, antes de nos embrenharmos nas compressões do filósofo alemão sobre o ceticismo e os céticos, parece-nos de grande valia perceber como o ceticismo é compreendido desde a visão de um cético. Nossa referência aqui é o texto de Sexto Empírico ${ }^{7}$, Hipotiposes pirrônicas, em seu primeiro livro, no qual o autor apresenta a diferença entre os sistemas filosóficos existentes no período em que viveu:

O resultado natural de qualquer investigação é que aquele que investiga ou bem encontra aquilo que busca, ou bem nega que seja encontrável e confessa ser inapreensível, ou ainda, persistem em sua busca. $\mathrm{O}$ mesmo ocorre com as investigações filosóficas, e é provavelmente por isso que alguns afirmam ter descoberto a verdade, outros que a verdade não pode ser apreendida, enquanto outros continuam buscando. Aqueles que afirmam ter descoberto a verdade sãos os "dogmáticos", assim chamados especialmente Aristóteles, por exemplo, Epicuro, os estóicos e alguns outros. Clitômaco, Carnéades e outros acadêmicos consideram a verdade inapreensível, e os céticos continuam buscando. Portanto, parece razoável

\footnotetext{
${ }^{5}$ Tanto Lopes (2008) quanto Sommer (2006) apontam para pontos de contato de Nietzsche com o ceticismo, que vão desde o seu período de formação até períodos posteriores (LOPES, 2008, p. 33-34; SOMMER, 2006, p. 259). Cf. também BETT, R. Nietzsche on the Skeptics and Nietzsche as Skeptic. In: Archiv für Geschichte de Philosophie. v. 82, n. 1, p. 62-86, 2000.

${ }^{6}$ Nossa posição neste texto tende a corroborar a leitura de Raoul Richter, em seu texto Der Skeptizismus in der Philosophie und seine Überwindung, de 1908, no qual, apesar de o autor colocar Nietzsche e os céticos em polos distintos, não deixa de afirmar Nietzsche como um cético (RICHTER, 1908, p. 463).

${ }^{7}$ Sexto viveu possivelmente entres os séculos I e II d. C.
} 
manter que há três tipos de filosofia: a dogmática, a acadêmica e a cética (SEXTUS, 1997, p. 115).

O ceticismo é entendido como um movimento filosófico que surgiu na Grécia antiga, por volta do século III a.C., tendo como marca a radicalização do exame crítico filosófico (BROCHARD, 2009, p. 7). Neste sentido, o "ataque negativo de Nietzsche à verdade ecoa do ceticismo antigo" (KAIN, 1983, p. 383. Tradução nossa), porém, ele não ocorre da mesma maneira.

Em Ecce homo, Nietzsche realiza um comentário acerca de sua leitura do livro de Victor Brochard, Les Sceptiques Grecs (1887), elogiando aos céticos por serem “o único tipo respeitável entre essa gente cheia de duplicidade - de quintuplicidade - que são os filósofos" (EH, ”Por que sou tão inteligente, §3). Ainda, em outras passagens de sua obra, encontramos elogios aos céticos, como, por exemplo, nos textos de A gaia ciência, aforismos 122 e 358; de Além de bem e mal, aforismo 54; da Genealogia da moral, na terceira dissertação, aforismo 24; de $O$ anticristo, nos parágrafos 12 e 24. Porém, também, não são poucas as vezes que localizamos críticas ao ceticismo e aos céticos, como ocorre em Além de bem e mal, aforismo 208; e nos fragmentos póstumos ${ }^{8}$.

Pensando a visão negativa que Nietzsche possui sobre céticos, ela vem de posições que o filósofo não assume para si. A primeira, que envolve um sentido epistemológico, diz respeito ao fato de que, para nosso filósofo, os céticos ainda mantêm a crença em uma verdade incondicionada, como ocorre com os céticos acadêmicos, o que pode ser logo percebido no texto do Hipotiposes, quando Sexto compara os sistemas filosóficos (SEXTUS, 1997, p. 115). Já acerca do pirronismo, não são poucas as vezes que Nietzsche, ao se referir Pirro de Élis ${ }^{9}$, o chama de decadente e budista, afirmando que o proceder do pirrônico leva à uma filosofia da paralisação da vontade de vida (KSA XIII, 14 [129]; XIII, 15 [58]; XIII, 14 [99]) e, por isso, inadequada ${ }^{10}$.

Seja como for, fica claro que, apesar de o ceticismo não ser o tema central da obra de Nietzsche, ou mesmo ser extenso tal qual sua discussão sobre o platonismo, por exemplo, é

\footnotetext{
${ }^{8}$ Cf. KSA VII, 5 [21]; XIII, 15 [58].

${ }^{9}$ Viveu, possivelmente, no século IV a.C.

${ }^{10}$ Para Nietzsche, o cético pirrônico cai na armadilha de apenas suspender o juízo e não realizar nenhuma afirmação positiva. Diferente do que ocorre com o cético pirrônico, Nietzsche possui objetivos assertivos; ou seja, ele realiza afirmações, o que faz com que sua posição não se compatibilize com a dos céticos antigos, chegando a afirmar que a ataraxia cética paralisa a vontade (BM, § 208). Cf. BETT, 2000, p. 78; SOMMER, 2006, p. 265; PARUSH, 1976, p. 537.
} 
inegável que ele possuía um conhecimento considerável sobre o ceticismo grego ${ }^{11}$ e suas apropriações durante a história da filosofia e, por isso, é inegável, também, que ele sofre influências desta tradição para a elaboração de sua filosofia. No entanto, o seu tom cético não se identifica com outras versões, antigas e modernas, do ceticismo. Se quisermos compreender qual é o ceticismo que Nietzsche prescreve para si, ele nos dá pistas quando afirma: "Ceticismo! Sim, mas um ceticismo de experimentos (KSA IX, 6 [356] $)^{12}$.

As passagens supracitadas nos possibilitam compreender em que sentido há ambiguidade na apreensão que Nietzsche possui do ceticismo: ao mesmo tempo em que ele rechaça o ceticismo, compreendido como uma paralização da vontade, ele também reclama para si um ceticismo que possibilita a experimentação. Isto é importante, dado que quando falamos de ceticismo em Nietzsche, ele não possui a significação que possui na obra de vários filósofos modernos, como René Descartes, David Hume e outros, nas quais ele é entendido apenas como uma ferramenta epistemológica (versão epistemológica do ceticismo). Em Nietzsche, o ceticismo tem papel fundamental, também, para as suas compreensões acerca de questões básicas sobre a vida (PARUSH, 1976, p. 523-524).

A compreensão do ceticismo presente em Nietzsche não se dá por acaso, mas sim graças à forma como o filósofo alemão compreende o que é ser filósofo. Utilizando-se de si como campo de experimentação para a construção da imagem do filósofo, Nietzsche compreende a necessidade de não se apegar à verdade, mas se utilizar das várias informações e posições em favor do seu serviço, conforme ele nos lembra em Além de bem e mal:

\begin{abstract}
Talvez para a educação do verdadeiro filósofo convirá que recorra e passe todos os degraus em que se detiveram aqueles trabalhadores científicos da filosofia; talvez deva ser crítico e cético, e dogmático, e adivinhador de charadas, e moralista, e vidente, e "espírito livre", percorrendo todo o recinto dos valores humanos e das avaliações de valor, para desfrutar de mil olhos e de mil consciências da altura para aquela longitude, da profundidade para aquela altura, do ângulo para aquela amplidão. Mas tudo isso não é senão uma condição preliminar de sua tarefa: a tarefa em si exige outra coisa muito diferente, a criação dos valores (BM, § 211).
\end{abstract}

Nestes termos, ser cético - ser um cético nietzschiano -, significa tornar-se um espírito livre, recusando cair na "tentação" da necessidade de qualquer absoluto, de qualquer compreensão e postura estanques. Ao lançar mão desta posição, o ceticismo de Nietzsche deve

\footnotetext{
${ }^{11}$ Por ser filólogo de formação, Nietzsche possuía um vasto conhecimento acerca da cultura e da filosofia grega antiga. Lembramos que ao longo da década de 70 Nietzsche ofereceu preleções acerca dos filósofos pré-socráticos e sobre os diálogos de Platão, na Universidade de Basel.

${ }^{12}$ Cf. KSA IX, 6 [442].
} 
ser visto como uma abertura à criatividade. Ao rejeitar a possibilidade de se suspender o juízo de maneira total, é fundamental que o ceticismo, em sua versão nietzschiana, seja percebido como a autoconsciência da impossibilidade de se tomar perspectivas como absolutas. Em outras palavras, "[p]ara ser um cético nietzschiano, é preciso superar a necessidade de ideias absolutas (MITCHESON, 2017, p. 76. Tradução nossa).

Destarte, a filosofia de Nietzsche deve ser compreendida como uma tentativa de libertar a criatividade humana e, por isso, ele se posiciona contrário a toda regulamentação da metafísica em suas várias representações (moral, religião, etc.). Nietzsche não se pretende à uma filosofia teleológica, o que se pode perceber pelo fato de não haver em seu pensamento nenhuma determinação interna e normativa que prescreva uma perspectiva, pois, em si, o próprio ato de prescrever limitaria o ato criador (SOMMER, 2014, p. 13).

O tema da criação, apesar de não ser tão recorrente na literatura nietzschiana, toma o centro de suas discussões a partir do último período de sua obra, sob a perspectiva da “transvaloração dos valores”, que surge em sua obra Além de bem e mal, de 1886 (BM, §203, 211). Isto posto, partindo do pressuposto de que o desenvolvimento da filosofia de Nietzsche se dá em uma evolução constante de sua relação com o ceticismo e dos desdobramentos que se dão a partir desta relação, como seria possível alinhar o ceticismo com a tarefa de transvalorar, cara ao filósofo alemão em sua obra tardia? Questão que pretendemos que nos guie na reflexão que se seguirá na próxima seção.

\title{
OBRA TARDIA: UMA RECONCILIAÇÃO COM O CETICISMO?
}

\begin{abstract}
Alargar o futuro a sua mão criadora, e tudo o que é, e tudo o que foi, tornar-se para eles um meio, um instrumento, um martelo. Seu proceder equivale a criar, seu criar equivale a legislar, sua vontade da verdade equivale à vontade de potência. Existem hoje semelhantes filósofos? Já havia tais filósofos? Não é necessário que existam? (BM, §211).
\end{abstract}

Se no período intermediário dos escritos de Nietzsche ele se refere por diversas vezes ao ceticismo, porém de forma ambígua, em sua obra tardia a frequência de referências diminui. Richard Bett, no texto Nietzsche on the Skeptics and Nietzsche as skeptic (2000), defende que há diferenças entre a presença do ceticismo nestes dois períodos. A primeira é que as avaliações que Nietzsche realiza do ceticismo na obra madura passam a ser mais francas. A segunda é que o ceticismo passa a ser visto como uma necessidade, como podemos notar no aforismo 211 de Além de bem e mal, diferentemente do que vinha ocorrendo nas obras anteriores (BETT, 2000, 
p. 79). Isto não significa que neste período não haja críticas erigidas pelo filósofo ao ceticismo, elas existem, como se pode perceber nos aforismos 208 e 209 de Além de bem e mal. Entretanto, neste período, Nietzsche já possui clareza acerca de suas intenções literárias e, neste sentido, a controvérsia presente nas afirmações e utilizações que ele realiza do ceticismo têm agora um objetivo, seja qual for, que é publicar uma obra capital, sob o título " $A$ vontade de poder. Ensaio de transvaloração dos valores" (GM III, §27), o que de fato não ocorreu ${ }^{13}$.

Deixado de lado o projeto de escrever a obra "A vontade de poder. Ensaio de Transvaloração dos valores", em 1888, Nietzsche acredita ter realizado o seu projeto de Transvaloração em $O$ anticristo, conforme podemos notar em missiva a Paul Deussen, de 26 de novembro de $1888^{14}$ :

\begin{abstract}
Minha vida agora alcança seu ápice: mais alguns anos, e a terra tremerá com tremendos relâmpagos. - Juro que tenho forças para alterar a cronologia. - Não há nada que hoje permaneça que não desmorone, eu sou mais dinamite que um ser humano. - Minha Transvaloração de todos os valores, com o título principal de $\mathrm{O}$ ANTICRISTO, está terminada (BVN 1888, 1159. Tradução nossa).
\end{abstract}

$\mathrm{Na}$ referida obra, Nietzsche realiza comentários ao ceticismo (AC, §12, 54). Particularmente, no parágrafo 54, o autor não apenas traça elogios ao ceticismo, como ocorre no parágrafo 12, mas afirma: “[n]ão nos enganemos: grandes espíritos são céticos. Zaratustra é um cético". Nota-se, ainda, que o ceticismo, nesta obra, neste parágrafo, se encontra vinculado a uma posição afirmativa, na qual busca-se a experimentação de convicções, porém como um meio. Desta forma, o ceticismo a que Nietzsche se aproxima é um tipo de filosofia que propicia o querer. Isto significa que quando o autor alemão afirma um certo tipo de ephexis, ela não é tratada como um fim, mas como um meio para se criar interpretações do mundo e de si (WOTLING, 2010, p. 114).

A quintessência da relação de Nietzsche com o ceticismo, e nos termos propostos nesta seção, a conciliação operada por ele para com o ceticismo, não significa um acatamento das posições céticas antigas e modernas de forma integral. De qualquer maneira, ao se tentar relacionar o filósofo alemão com o ceticismo, devem-se deixar de lado as interpretações historicamente firmadas acerca desta tradição filosófica (SOMMER, 2006, p. 2660). Com isso,

\footnotetext{
${ }^{13}$ RUBIRA, L. A tarefa de transvaloração: esclarecimentos a partir da correspondência de Nietzsche em 1888. In: Discurso. v. 1, n. 2, p. 135-154, 2018.

${ }^{14}$ A citação de cartas segue a organização de Paolo D'Iorio com base no trabalho de Colli e Montinari disponibilizadas no portal Nietzsche Source (www.nietzschesource.org). A edição eKGWB apresenta, além das cartas, diversas correções filológicas em relação à KSA e a KSB.
} 
temos a seguinte proposição: se o ceticismo não nos servir para questionarmos nossas crenças, para dissecar aquilo que se encontra por detrás de construções de conhecimento e moral que sublimam aquilo que somos - aquilo que é o ser humano - e, com isso, nos capacitar para a criação de novas maneiras de viver e ser, ele deve ser rechaçado. Diferentemente do "cético tradicional", Nietzsche tem objetivos positivos e sua linguagem e atuação filosófica são propositivas. Se, como vimos, ele desfere críticas ao ceticismo antigo, acusando-lhe de paralisar a vontade (principalmente o pirronismo) (BM, §208), ele reclama para si - como uma necessidade - um ceticismo de outra natureza; um ceticismo forte, que cria valores (BM, §209211).

Assim, é necessário reconhecer que o ceticismo em Nietzsche possui, ao seu modo, um papel terapêutico, capaz de curar e tornar saudável (MITCHESON, 2017, p. 68). O ceticismo na obra nietzschiana não pode ser compreendido como estando distante daquilo que é a essência de seu esforço por criar uma filosofia da vitalidade. Sommer defende que neste período - na obra tardia - há a presença de um “ceticismo criador” (SOMMER, 2014, p. 25-26).

Em $O$ anticristo culmina uma avaliação positiva do ceticismo enquanto há um movimento de reavaliação dos valores (LOPES, 2008, p. 529). Por esse motivo, gostaríamos de retornar aos dois parágrafos de $O$ anticristo $(12,54)$, já citados anteriormente. Vamos a eles:

\footnotetext{
Ponho de lado alguns céticos, o tipo decente na história da filosofia: mas o restante não conhece as exigências primeiras da retidão intelectual. Fazem todos eles como as mulherzinhas, esses grandes entusiastas e prodígios - já tomam os "belos sentimentos" por argumentos, o "peito erguido" por um fole da divindade, a convicção por critério de verdade (AC, $\S 12)$.
}

Que ninguém se deixe induzir ao erro: grandes espíritos são céticos. Zaratustra é um cético. A força, a liberdade que vem da força e sobreforça do espírito, prova-se através do ceticismo. Homens de convicção não devem ser levados em conta em nada fundamental referente a valor e desvalor. Convicções são prisões. Eles não vêem longe o bastante, não vêem abaixo de si: mas, para poder falar sobre valor e desvalor, é preciso ver quinhentas conviç̧ões abaixo de si - atrás de si... Um espírito que quer coisas grandes, que quer também os meios para elas, é necessariamente um cético. Ser livre de todo tipo de convicção faz parte da força, poder olhar livremente... (AC, §54).

No que diz respeito ao parágrafo 12 , de pronto, vemos na sequência do texto a contraposição que o autor realiza entre os céticos e Kant, o que é revelador, dado que esclarece que $O$ anticristo não é somente uma refutação às pretensões dogmáticas do cristianismo, mas também àquela defendida sob a égide da moral kantiana. Lopes, chama-nos a atenção para o fato de que neste parágrafo de $O$ anticristo, o que Nietzsche estaria realizando é uma oposição 
do cético, como representante da integridade intelectual (o que estaria aproximando Nietzsche de uma posição levada a cabo pelo ceticismo acadêmico), ao filósofo de Königsberg, que era visto por ele como o último representante de uma apropriação indevida do ceticismo, em favor do cristianismo (LOPES, 2008, p. 534).

Por outro lado, Sommer, em seu minucioso comentário ao $O$ anticristo, propõe que não só esta obra, mas as demais obras do período tardio de Nietzsche sejam lidas sob a luz do parágrafo 54 (SOMMER, 2000, p. 475-539). O intérprete alemão, partindo da leitura do §54, propõe que Nietzsche é um cético pirrônico e que seus argumentos possuem valor circunstancial; em outras palavras, que a defesa de argumentos realizada pelo autor de $O$ anticristo muda, dependendo das circunstâncias e objetivos que o estariam movendo em cada momento (SOMMER, 2000, p. 539). Lopes, apesar de concordar com o fato de não haver uma diferença entre as estratégias argumentativas utilizadas pelo cético pirrônico e por Nietzsche, aponta que são as motivações nietzschianas que o afastam do ceticismo pirrônico. Se o pirrônico procede com a suspensão do juízo, a sua intenção é alcançar a tranquilidade mental e uma moderação dos afetos, o que de maneira alguma é perseguido por Nietzsche (LOPES, 2008, p. 537).

É profícuo, com isto, compreender que quando se fala de haver uma conciliação de Nietzsche com o ceticismo em sua obra tardia, ele se dá em três movimentos, diga-se assim, principalmente em $O$ anticristo: o primeiro movimento, trata-se de criticar as apropriações indevidas do ceticismo ao longo da história da filosofia - leia-se modernidade -, o que pode ser percebido nos aforismos 10,11, 12, 55, 61, em que erige críticas a Kant, e 5, onde realiza um comentário a Pascal; o segundo movimento, trata-se daquele em que se identifica o ceticismo que Nietzsche recomenda e reclama para si, o qual permite a experimentação e possibilita a criação; e o terceiro movimento, trata-se daquele em que se percebe a compreensão que o filósofo alemão possui do ceticismo grego, sem, por outro lado, condená-lo (LOPES, 2008, p. $544-545)^{15}$.

Por fim, com tudo que foi exposto, nota-se que a relação de Nietzsche com o ceticismo passa por modulações, aproximações e distanciamentos durante toda a sua vida intelectualmente ativa. Esteve o ceticismo presente na crise instaurada no jovem filólogo, no período intermediário e, também, em seu período maduro, quando ele elabora "sua filosofia",

\footnotetext{
${ }^{15}$ Se no texto de $O$ anticristo não encontramos críticas claras ao ceticismo grego, isto não ocorre nos póstumos. Por exemplo, em um fragmento de 1888 o ceticismo é definido como "resultado da decadência" (KSA XIII, 13 [86]).
} 
no qual o ceticismo esteve presente como um caminho que possibilita o ato criativo e não engessa a vontade humana, dando "o direito de criar" (KSA X, 6 [1]. Tradução nossa). Exclama Nietzsche: “[e]u elogio todo ceticismo ao qual posso responder: “Tentemos!” (GC, §51). Seja qual for este ceticismo, ele é aquele que permite ao ser humano compreender-se senhor e servo de si, em favor de si - vocação dos "verdadeiros filósofos", que não podem ser outra coisa senão "legisladores" (BM, §211).

\section{CONCLUSÃO}

Pelo nosso itinerário, guiado pelas leituras realizadas pelos autores que se propuseram a tratar da problemática do ceticismo presente na obra e no pensamento nietzschianos, nos deparamos com a inevitável necessidade de se dar atenção à experiência do ceticismo pela qual passou Nietzsche. Dada esta atenção, o que se nota é que é primordial compreender que o ceticismo não é a defesa de uma posição unívoca frente à vida e às questões filosóficas e, por isso, podemos localizar semelhanças entre a filosofia nietzschiana e a cética, entre as quais podemos apontar a crítica ao dogmatismo e à sua pretensão universalizante de argumentos, conceitos e verdades.

Outra questão que se nos apresenta é que para tratarmos da presença do ceticismo na obra tardia de Nietzsche, é preciso ter a consciência da existência de três posições suas sobre esta forma de filosofia, como pudemos ver anteriormente: aquela em que ele rechaça as apropriações indevidas presentes na longa história da filosofia no Ocidente - principalmente na modernidade; aquela em que é possível compreender o seu conhecimento do ceticismo grego e suas pretensões, as quais ele não prescreve ou mesmo toma para si, mas também não crítica ferrenhamente, ao menos nos textos publicados; e aquela em que vemos Nietzsche reclamando para si um novo tipo de ceticismo; um ceticismo de força, que propicia a criação e experimentação; que não toma qualquer consideração como possuidora de uma validade universal e nem como inválida, mas como um interpretação possível na tarefa de "tornar-se o que se é” (EH, Por que sou tão inteligente, §9).

Por fim, este texto gostaria de ser lido como um estudo introdutório à uma pesquisa mais ampla. Certamente, houve pontos insuficientes e, em decorrência disto, lacunas não preenchidas. Entretanto, espera-se que ela aponte para meandros pouco esclarecidos da obra nietzschiana a serem perscrutados. 


\section{REFERÊNCIAS}

ABEL, Güten. Verdade e interpretação. Tradução: Claudemir Luís Araldi; revisão: André Luís Mota Itaparica. In: MARTON, S. (org.). Nietzsche na Alemanha. p. 179-198. São Paulo: Discurso Editorial; Ijuí: Editora Ijuí, 2005. (Coleção sendas e veredas. Série recepção).

BELLORO, Lucia Ana. Une approche à "l'ultime scepticisme" nietzschéen: Quelle est la voie sceptique de Zarathoustra?. In: Ipseidas. v. 1, n. 2, p. 66-75, 2015.

BETT, Richard. Nietzsche on the Skeptics and Nietzsche as Skeptic. In: Archiv für Geschichte de Philosophie. v. 82, n. 1, p. 62-86, 2000.

BROCHARD, Victor. Os céticos gregos. Tradução: Jaimir Conte. São Paulo: Edysseus Editora, 2009.

CLARK, Maudemarie. Nietzsche on truth and philosophy. Cambridge: Cambridge University Press, 1990.

DE SOUSA, Mauro Araújo. Nietzsche: para uma crítica à ciência. São Paulo: Paulus, 2011.

GIACOIA JÚNIOR, Oswaldo. Labirintos da alma: Nietzsche e a auto-supressão da moral. Campinas: Editora da UNICAMP, 1997.

KAIN, Philip. Nietzsche, Skepticism and Eternal Recurrence. In: Canadian Journal of Philosophy. v. 13, n. 3, p. 365-387, p. 1983. Disponível em: http://www.jstor.org/stable/40231327. Acesso 10 abr. 2020.

LOPES, Rogério. Elementos de retórica em Nietzsche. São Paulo: Edições Loyola, 2006.

LOPES, Rogério. Ceticismo e vida contemplativa em Nietzsche. 2008. Tese (Doutorado em Filosofia) - Faculdade de Filosofia e Ciências Humanas da UFMG. Belo Horizonte, 2008.

MACHADO, Roberto. Nietzsche e a verdade. Rio de Janeiro/São Paulo: Paz e Terra, 2017.

MAGNUS, Bernd. Nietzsche Mitigated Skepticism. In: Nietzsche-Studien. v. 9, n. 1, p. 260267, 1980. Disponível em: https://doi.org/10.1515/9783110244298.260. Acesso em: 13 abr. 2020 .

MITCHESON, Katrina. Scepticism and self-transformation in Nietzsche - On the uses and disadvanceges of a comparison to Pyrrohonian Scepticism. In: British Journal for the

History of Philosophy. v. 25, n. 1, p. 63-83, 2017. Disponível em: https://uwerepository.worktribe.com/output/889514. Acesso em: 12 ago. 2019.

NIETZSCHE, Friedrich. Digitale Kritische Gesamtausgabe von Nietzsche Werken und Briefen. Edição organizada por Paolo D’ Iorio, baseada na edição crítica de Giogio Colli e Mazzimo Montinari e publicada pela Nietzsche Source. Edição eletrônica. Disponível em: https://www.nietzschesource.org/\#eKGWB. Acesso em 20 mai. 2020. 
NIETZSCHE, Friedrich. Sämtliche Werke. Kritische Studienausgabe (= KSA: 15 vols.). Hrsg. von Giorgio Colli und Mazzino Montinari. Berlin/New York: Walter de Gruyter, 1999.

NIETZSCHE, Friedrich. Sämtliche Werke. Kritische Gesamtausgabe (= KGW). Hrsg. von Giorgio. Colli und Mazzino Montinari. Berlim/New York: Walter de Gruyter, 1995.

NIETZSCHE, Friedrich. Ecce Homo: Como alguém se torna o que é. Tradução, notas e posfácio: Paulo César de Souza. São Paulo: Companhia das Letras, 1995.

NIETZSCHE, Friedrich. Humano, demasiado humano: um livro para espíritos livres. Tradução, notas e posfácio: Paulo César de Souza. São Paulo: Companhia das Letras, 2000.

NIETZSCHE, Friedrich. Sobre verdade e mentira. Tradução e organização: Fernando de Moraes Barros. São Paulo: Hedra, 2008.

NIETZSCHE, Friedrich. Genealogia da moral: uma polêmica. Tradução, notas e posfácio: Paulo César de Souza. São Paulo: Companhia das Letras, 2009.

NIETZSCHE, Friedrich. A gaia ciência. Tradução, notas e posfácio: Paulo César de Souza. São Paulo: Companhia das Letras, 2012a.

NIETZSCHE, Friedrich. Além do bem e do mal: prelúdio de uma filosofia do futuro. Tradução: Mário Ferreira dos Santos. Petrópolis: Vozes, 2012 b.

NIETZSCHE, Friedrich. O anticristo: maldição ao cristianismo/Ditirambos de Dioníso. Tradução. Notas e posfácio: Paulo César de Souza. São Paulo: Companhia de Bolso, 2016.

PARUSH, Adi. Nietzsche on the Skeptic's life. In: The Review of Metaphysics. vol. 29, n. 3, p. 523-542, 1976. Disponível em: http://www.jstor.org/stable/20126816. Acesso em: 06 abr. 2020 .

RICHTER, Raoul. Der Skeptizismus in der Philosophie und seine Überwindung. (02 vols.) Leipzig: Dürr'sche Buchhandlung, 1908.

RUBIRA, Luis. A tarefa de transvaloração: esclarecimentos a partir da correspondência de Nietzsche em 1888. In: Discurso. v. 1, n. 2, p. 135-154, 2018. Disponível em:

https://www.revistas.usp.br/discurso/article/view/150914/147878. Acesso em: 20 mai. 2020.

SEXTUS, Empirico. Hipotiposes Pirrônicas - Livro I. Tradução: Danilo Marcondes de Souza Filho. In: O que nos faz pensar, v. 9, n. 12, p. 115-122, 1997. Disponível em:

http://www.oquenosfazpensar.fil.puc-rio.br/index.php/oqnfp/article/view/130. Acesso em: 04 dez. 2018.

SOMMER, Andreas Urs. Friedrich Nietzsches "Der Antichrist". Ein

philosophischhistorischer Kommentar. Basel: Schwabe, 2000.

SOMMER, Andreas Urs. Nihilism and Skepticism in Nietzsche. In: PEARSON, K. A. (org.). A companion to Nietzsche. p. 250-269. Oxford: Blackwell, 2006. 
SOMMER, Andreas Urs. Criatividade e ceticismo em Nietzsche. In: Cadernos Nietzsche. v. 1, n. 34, p. 11-31, 2014.

STEGMAIER, Werner. As linhas fundamentais do pensamento de Nietzsche: coletânea de artigos: 1985-2009. Organização: Jorge Luiz Viesenteiner e André Luis Muniz Garcia.

Petrópolis: Vozes, 2013.

WOTLING, Patrick. "Cette espèce nouvelle de Scepticisme, plus dangereuse et plus dure". Ephexis, Biddhisme, frédéricisme chez Nietzsche. In: Revue de métaphysique et de morale. v. 1, n. 65, p. 109-123, 2010. Disponível em: https://www.cairn.info/revue-de-metaphusiqueet-de-morale-2010-1-page-109.htm. Acesso em 30 mar. 2020. 